\title{
Characterization of floc structure and strength: Role of changing shear rates under various coagulation mechanisms
}

\author{
Dongsheng Wang ${ }^{\mathrm{a}, *}$, Ruobing $\mathrm{Wu}^{\mathrm{a}}$, Yunzhong Jiang ${ }^{\mathrm{b}}$, Christopher W.K. Chow ${ }^{\mathrm{a}, \mathrm{c}}$ \\ a State Key Laboratory of Environmental Aquatic Chemistry, Research Center for Eco- Environmental Sciences, Chinese Academy of Sciences, B0X2871, Beijing 100085, China \\ ${ }^{\mathrm{b}}$ China Institute of Water Resources and Hydropower Research, Beijing 100038, China \\ ${ }^{\mathrm{c}}$ Australian Water Quality Centre, 250 Victoria Square, Adelaide, SA 5000, Australia
}

\section{A R T I C L E I N F O}

\section{Article history:}

Received 28 June 2010

Received in revised form

18 November 2010

Accepted 19 November 2010

Available online 26 November 2010

\section{Keywords:}

Fractal dimension

Flocculation

Floc strength

Size distribution

Shear rate

\begin{abstract}
A B S T R A C T
The floc formation, structure and strength remain a problematic topic to be addressed clearly to guide the flocculator design. To study the relationship among floc structure, strength, size distribution, and fractal dimensions, the alum-kaolin flocs formed under different coagulation stages and mechanisms were investigated at various agitation rates. A new method based on the fractal theory was employed to analyze the strength of flocs. The relationship between fractal dimensions and floc size distribution was then discussed with controlled experiments, providing comparison between calculation results of the new method and the strength factor as well. The results show that both size and fractal dimension of flocs decrease with increasing shear rate. The floc strength follows the hierarchy: gradually increased shear rate from $40 \mathrm{rpm}$ to $60 \mathrm{rpm}>$ stable $60 \mathrm{rpm}$ shear rate > gradually decreased shear rate from $60 \mathrm{rpm}$ to $40 \mathrm{rpm}>$ stable $40 \mathrm{rpm}$ shear rate. Flocs formed under gradual shear increasing could easily re-flocculate and recover their strength after breakage.
\end{abstract}

(ㄷ) 2010 Elsevier B.V. All rights reserved.

\section{Introduction}

Coagulation and flocculation, based on hydrolyzing metal salts, are widely applied processes to remove suspended colloid particles and natural organic matter in water and wastewater treatment. There are mainly two mechanisms in the metal salts coagulation, i.e., charge neutralization and sweep flocculation [1]. Generally, the effectiveness of flocculation is measured by the parameters such as residual turbidity or DOC removal because they are directly related to the solid-liquid separation and water quality. However, they provide only limited information on flocculation process. The information of floc size distribution and structure would be much expected [2].

The steady-state floc size distribution is influenced by the balance between rate of aggregation and breakage [3-5]. The physicochemical and hydrodynamic conditions play significant roles simultaneously. The evolution of floc size distribution during flocculation is accompanied by the change of floc structure. The fractal structure of flocs had been observed, measured and analyzed by experimental, numerical simulation or theoretical methods [6-18]. However, from numerical simulation and theoretical perspectives, available researches focused mainly on the computer simulation, geometry analysis and material conservation [15-20].

\footnotetext{
* Corresponding author. Tel.: +86 1062849138; fax: +86 1062923541.

E-mail address: wgds@rcees.ac.cn (D. Wang).
}

For example, according to the concept of diffusion-limited aggregation (DLA) and other theoretical analysis, there are several active sites on the surface of fractal aggregates [16-18]. The evolution of fractal structure with continuously changing of shear condition and the mechanism involved have not been given sufficient attention [15].

Floc strength is another particularly important characteristic and plays a significant role in the effectiveness of water treatment plants. Water treatment processes are often non-ideal with many possible zones of higher shear forces that will induce breakup of floc. Flocs must resist these stresses to prevent being broken into smaller clusters because, in practical sense, small clusters generally have lower removal efficiencies. Generally, floc strength is considered to be dependent on the bonding of colloid particles in the aggregates [4,21-23]. As an assumption, the compactness of flocs is positively related to floc strength, however, there is no reasonable mechanic method to evaluate this relationship. Floc strength is directly related to floc structure and is, therefore, highly dependent on the floc formation process. Fractal dimension is characterized as an essential parameter to describe the floc structure and influenced comprehensively by the physicochemical and hydrodynamic conditions such as $\mathrm{pH}$ value, shear conditions, and types of coagulants and colloid particles [24-28].

In order to investigate the evolution of fractal structure and strength of flocs, a new method to calculate the strength of flocs was introduced and the calculation results were compared with the results of strength factor determined by small angle 


$\begin{array}{ll}\text { Nomenclature } \\ N_{f} & \text { the population of flocs } \\ M_{f} & \text { the mass of flocs } \\ V_{f} & \text { the volume of flocs } \\ \lambda & \text { the compactness of flocs } \\ \varepsilon & \text { the porosity of flocs } \\ \sigma_{T} & \text { the tensile strength of flocs } \\ F & \text { bonding force between primary particles } \\ d_{0} & \text { the size/diameter of primary particles } \\ d_{f} & \text { the size of stable flocs } \\ \tau_{B} & \text { Bingham critical shear stress of flocs } \\ D_{F} & \text { fractal dimension }\end{array}$

laser light scattering technology. Based on the concept of RLCCA (reaction limited cluster-cluster aggregation) and DLCCA (diffusion limited cluster-cluster aggregation) model, fractal dimensions of flocs formed in different shear conditions and coagulation mechanics were analyzed. The mechanism of restructure was also discussed. Finally, the relationship between fractal dimension and floc strength was discussed using the new method.

\section{Method development}

Two fundamental approaches have been taken in measuring floc strength [4]. One is the macroscopic measurement and the other is microscopic measurement. The macroscopic measurement is more often be utilized and focused on the energy required in a system for floc breakage. Meanwhile, some useful parameters such as floc strength factor and FI index were induced [13,24,25]. Strength factor and recovery factor can be defined as [13]:

strength factor $=\frac{d(2)}{d(1)} \times 100$

recovery factor $=\frac{d(3)-d(2)}{d(1)-d(2)} \times 100$

$d(1)$ and $d(3)$ represents the stable floc size before and after breakage, while $d(2)$ represents the floc size during breakage.

Jarvis et al. [13] investigated strength of NOM flocs coagulated with different coagulants by small angle laser light scattering technology and concluded that the strength of flocs is in the order: PDAMDAC flocs > ferric flocs > alum flocs. Gregory [25] used photometric dispersion analyzer to study the breakage and recovery behaviors of kaolin particles and found that the reversibility of PDAMDAC flocs were better than alum flocs.

Previously, Meakin [29] concluded that the fractal dimension was related with the population and mass of flocs by:

$N_{f}=\left(\frac{d_{f}}{d_{0}}\right)^{D_{F}}$

$M_{f}=\frac{\pi}{6} \rho_{0} d_{0}^{3-D_{F}} d_{f}^{D_{F}}$

Because of the volume of flocs was calculated by $V_{f}=\pi / 6 d_{f}^{3}$, the compactness of flocs can be expressed as:

$\lambda=\frac{(\pi / 6) d_{0}^{3} N_{f}}{(\pi / 6) d_{f}^{3}}=\left(\frac{d_{f}}{d_{0}}\right)^{D_{F}-3}$

Thus, the porosity of flocs can be determined by:

$\varepsilon=1-\lambda=1-\left(\frac{d_{f}}{d_{0}}\right)^{D_{F}-3}$
Taking account of the study by Tang et al. [30], strength of fractal aggregates is calculated by:

$\sigma_{T}=1.1 \frac{1-\varepsilon}{\varepsilon} \frac{F}{d_{0}^{2}}$

$\sigma_{T}, F, \varepsilon$ and $d_{0}$ represent the tensile strength of aggregates, the bonding forces between primary particles, the porosity of aggregates and the diameter of primary particles, respectively. In addition, the Bingham critical shear stress, which has a tight relationship with the concentration of particles and the fractal dimension, provides a fine estimation to the floc strength based on the concept of self-similar floc structure [31-33]:

$\tau_{B} \propto \varphi^{2 /\left(3-D_{F}\right)}$

If considering the flocs as sphere and using $\tau_{B}$ to replace $\sigma_{T}$, Eq. (7) can be equivalently written as:

$\tau_{B}=1.1 \frac{1-\varepsilon}{\varepsilon} \frac{F}{d_{0}^{2}}$

Based on the Eq. (6), Eq. (9) can be replaced by:

$\tau_{B}=1.1 \frac{\left(d_{f} / d_{0}\right)^{D_{F}-3}}{1-\left(d_{f} / d_{0}\right)^{D_{F}-3}}\left(\frac{F}{d_{0}^{2}}\right)$

Finally, the strength of flocs can be calculated by Eq. (10).

\section{Materials and methods}

\subsection{Suspension preparation and coagulant}

Kaolin was used as primary particles in this experiment and the solid concentration of suspension was $137 \mathrm{~g} / \mathrm{L}$ determined by gravimetry. During the high-shear condition, $300 \mathrm{~g}$ of kaolin was dispersed in $1000 \mathrm{ml}$ of deionized water. After 30-min mixing, the $\mathrm{pH}$ of suspension was adjusted to $7.50 \pm 0.05$ (MP220, MettlerToledo, Switzerland) by adding $0.1 \mathrm{~mol} / \mathrm{L} \mathrm{NaOH}$ and the blending suspension was settled for $24 \mathrm{~h}$ in a measuring cylinder. Then the top suspension was decanted into another container as the model suspension. The average size of the particles in suspension was closed to $4 \mu \mathrm{m}$, measured by laser light scattering (Mastersizer 2000, Malvern, UK).

The kaolin concentration of $50 \mathrm{mg} / \mathrm{L}$ was prepared by diluting the stock suspension with tap water. In addition, a small amount of humic acid was added into the raw suspensions in order to avoid the disturbance of $\mathrm{Ca}^{2+}$ and $\mathrm{Mg}^{2+}$ in tap water [25]. The $\mathrm{pH}$ value of raw suspension was $7.68 \pm 0.10$ and the suspensions used in experiment was adjusted to $7.50 \pm 0.05$ by adding $0.1 \mathrm{~mol} / \mathrm{L} \mathrm{HCl}$. All of the experiments were preceded in room-temperature $\left(23^{\circ} \mathrm{C} \pm 2\right)$ and repeated three times.

Alum $\left(\mathrm{Al}_{2}\left(\mathrm{SO}_{4}\right)_{3} \cdot 18 \mathrm{H}_{2} \mathrm{O}\right.$, analytic reagent) was used as coagulant to form colloid aggregates. Stock alum solutions were prepared as $0.1 \mathrm{M}$ solution in deionized water.

\subsection{Floc structure analysis}

The experiment was conducted in 1-1 beaker with $800 \mathrm{ml}$ diluted kaolin suspension. The rotary speeds and the stirring times of the impellers can be pre-set.

Fractal dimension of colloid aggregates was measured by light scattering [34]. The light intensity scattered by particles, is proportional to the particles size. Small particles scatter light at high angles, while large particles scatter at lower angles. In light scattering study, the scattered intensity as a function of the magnitude of the scattering wave vector, $Q$ is measured, where,

$Q=\frac{4 \pi n \sin (\theta / 2)}{\lambda}$ 
Table 1

Description of the detailed steps of different control experiments.

\begin{tabular}{|c|c|}
\hline Experiment mode & Description \\
\hline $40+60$ (gradually increased shear) & $40 \mathrm{rpm}(5 \mathrm{~min})+45 \mathrm{rpm}(5 \mathrm{~min})+50 \mathrm{rpm}(5 \mathrm{~min})+55 \mathrm{rpm}(5 \mathrm{~min})+60 \mathrm{rpm}(5 \mathrm{~min})+400 \mathrm{rpm}(2 \mathrm{~min})+40 \mathrm{rpm}(20 \mathrm{~min})$ \\
\hline $60+40$ (gradually decreased shear) & $60 \mathrm{rpm}(5 \mathrm{~min})+55 \mathrm{rpm}(5 \mathrm{~min})+50 \mathrm{rpm}(5 \mathrm{~min})+45 \mathrm{rpm}(5 \mathrm{~min})+40 \mathrm{rpm}(5 \mathrm{~min})+400 \mathrm{rpm}(2 \mathrm{~min})+40 \mathrm{rpm}(20 \mathrm{~min})$ \\
\hline 40 (stable 40 rpm shear) & $40 \mathrm{rpm}(25 \mathrm{~min})+400 \mathrm{rpm}(2 \mathrm{~min})+40 \mathrm{rpm}(20 \mathrm{~min})$ \\
\hline 60 (stable $60 \mathrm{rpm}$ shear) & $60 \mathrm{rpm}(25 \mathrm{~min})+400 \mathrm{rpm}(2 \mathrm{~min})+40 \mathrm{rpm}(20 \mathrm{~min})$ \\
\hline
\end{tabular}

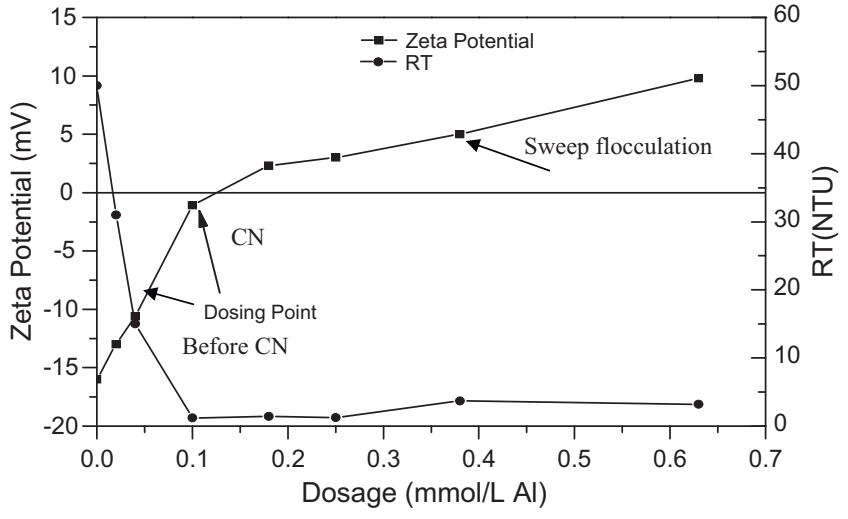

Fig. 1. An illustration of dosing point which was used in the experiments.

$n, \theta$, and $\lambda$ are the refractive index of the medium, the scattered angle, and the wavelength of radiation in vacuum, respectively. It has been shown that for a mass fractal aggregate, it satisfies the conditions for Rayleigh-Gans-Debye (RGD) regime, the scattered intensity $I$ can be described by the following equation:

$I \propto Q^{-D_{F}}$

Thus, there should be a linear region on a log-log plot, with a slope of $-D_{F}$. Based on the result of Spicer et al. and other researchers [12,35], the range of floc diameter of the controlled experiments is suitable to apply the RGD theory to calculate floc fractal dimensions.

\subsection{Experimental procedure}

The dosing point of coagulant at charge neutralization was determined by pre-jar test with $800 \mathrm{ml}$ of test suspension (Fig. 1). Zeta potential was measured by Zetasizer2000 (Malvern, UK). The pre-jar test was carried out as following: a rapid mixing at $200 \mathrm{rpm}$ for $1 \mathrm{~min}$, followed by slow stirring at $40 \mathrm{rpm}$ for $15 \mathrm{~min}$.

Alum dosage was carried out at $0.1 \mathrm{mmol} / 1$ closed to the charge neutralization point at all the jar tests. The scheme of control experiments for further research was shown in Table 1.

Taking the " $40+60$ " as the example, flocculation experiments were carried out as follows: rapid mixing at $200 \mathrm{rpm}$ for $1 \mathrm{~min}$ and the required amounts of alum was added to the beaker at the beginning of rapid mixing, followed by slow stirring at $40 \mathrm{rpm} 5 \mathrm{~min}$, and followed by a further slow stirring at $45 \mathrm{rpm}, 50 \mathrm{rpm}, 55 \mathrm{rpm}$ and $60 \mathrm{rpm}$ for $5 \mathrm{~min}$, respectively, then a breakage stage at $400 \mathrm{rpm}$ for $2 \mathrm{~min}$ was used, finally, the flocs regrew for $20 \mathrm{~min}$ at $40 \mathrm{rpm}$. The other processes in Table 2 are similar to those of " $40+60$ ".

Table 2

Strength factor and recovery factor of the flocs formed.

\begin{tabular}{lll}
\hline Runs & Strength factor & Recovery factor \\
\hline $40+60$ & 46 & 63 \\
$60+40$ & 37 & 50 \\
40 & 18 & 37 \\
60 & 40 & 67 \\
\hline
\end{tabular}

Dynamic aggregate size during growth and breakage was measured by laser scattering (Mastersizer 2000) when the jar test was proceeding. The suspension was monitored by drawing water through the optical unit of the Mastersizer and put back into the beaker by a peristaltic pump through plastic tubing with $5 \mathrm{~mm}$ inner diameter. In addition, the flow rate of pump was $25 \mathrm{ml} / \mathrm{min}$ in order to prevent the flocs from further aggregating or breakup. The pump was located downstream of the Mastersizer to avoid the effects of possible aggregates breakage in the pinch portion of pump. Moreover, size distributions were measured every $40 \mathrm{~s}$ taking into account of the duration of jar test.

\section{Results and discussion}

\subsection{Fractal dimension}

Fig. 2 shows the fractal dimension of flocs in the first controlled experiments. It was obviously that the fractal dimension of flocs increased as the flocs formation with different shear conditions adopted. The steady-state floc size distribution is a dynamic balance between aggregation and breakage [4] as aggregation and breakage always happen together with the growth of flocs. At the beginning of experiment, primary particles rapidly aggregate as the result of shear condition, simultaneously, some pores are formed in the inner of flocs. With the growth of flocs, cluster-cluster aggregation gradually plays an important role in the development of flocs. Some small but compact clusters will then have chance to penetrate into the inner pores of large flocs. As a result, the fractal dimension will be increased as the growth of flocs. It is easily understood that the higher the shear rate is, the more breaking possibility large flocs have. Thus, flocs formed in higher shear rate will have larger fractal dimension. Furthermore, it seems that flocs are sensitive to the change of shear conditions. Therefore, flocs formed in the " $40+60$ " conditions are more feasible to be broken and result in the highest fractal dimension by the floc re-structure as the shear rate gradually increasing.

It is generally considered that fractal structure will not be affected by breakage because the self-similarity of aggregates $[10,12,29]$, but this is not suitable for the flocs formed by electrostatic force. As shown in Fig. 2, there is some, even great, distinction of fractal dimensions after breakage, as considering the charge neutralization and sweeping flocs.

A possible explanation for these inconsistencies is that, although fractal structure or self-similarity is generally inspected in colloidal system [29], strictly self-similar structure is only an ideal concept and practical flocs are considered to have two or more characteristic fractal dimensions as a result of multilevel structure or multi-fractal characteristics $[13,36]$. Furthermore, self-similar fractal structure hardly relates to exterior conditions and evolution progress of floc growth.

Obviously, fractal dimension will be varied as exterior conditions such as the residual coagulant and primary particles have changed after breakage. Based on the DLA model and other available theoretical studies, growth of flocs always occurs in active sites. As a result, the size of flocs will achieve the balance with the shear condition although there are a large number of pores in the inner of flocs. Nevertheless, these pores have not achieved 

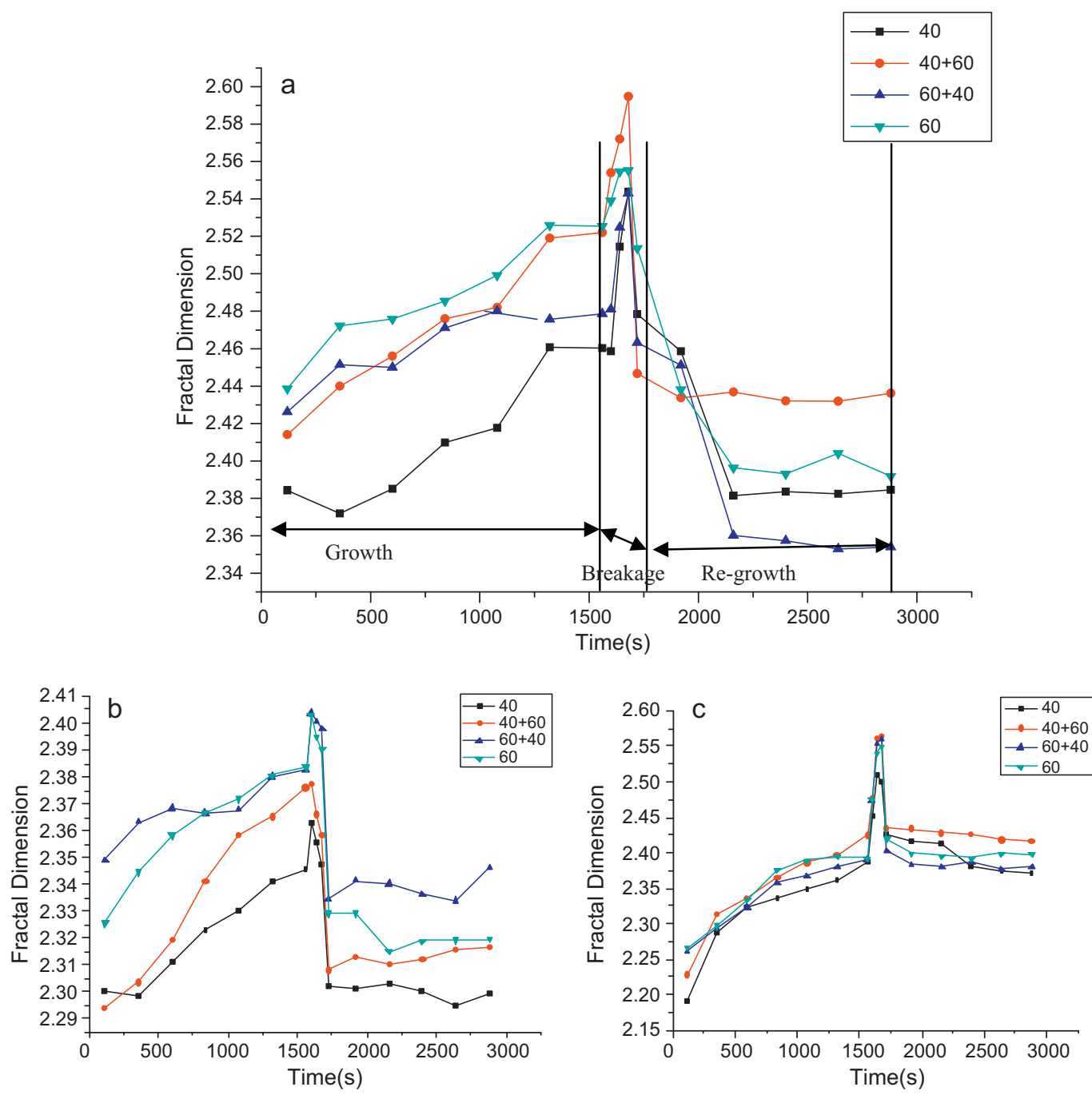

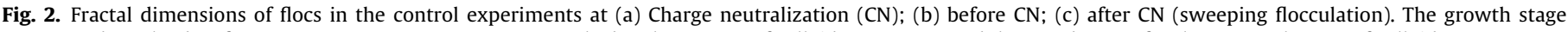
corresponds to the data from $0 \mathrm{~s}$ to $1500 \mathrm{~s}, 1500 \mathrm{~s}$ to $1680 \mathrm{~s}$ are the breakage stage of colloid aggregates, and the rest data are for the regrowth stage of colloid aggregates.

adsorption saturation and have the ability to combine with other particles or clusters further. Flocs which have achieved the size balance may have potential to make them more compact and finally improve the floc strength. In " $40+60$ " conditions, the shear rate gradually increases from $40 \mathrm{rpm}$ to $60 \mathrm{rpm}$, some of the surface bonds are more possible to be properly destroyed than other conditions because flocs are sensitive to the change of shear rate [37]. As result, some inner parts of flocs are exposed and filled by particles or clusters. Consequently, these flocs are more compact than clusters formed in stable shear rate conditions. Since floc structure is influenced by floc history, fractal dimension of flocs in " $40+60$ " is higher than those of " $60+40$ " and " 40 " flocs. Moreover, this explanation may provide another possible mechanism on floc history. Meanwhile, this is the reason why one of the experiments is designed as the gradually increased shear rate.

During the breakage stage, fractal dimensions of flocs are higher than the fractal dimension of flocs before breakage. This phenomenon is consistent with a number of other studies [12,13], and can be explained by floc rearrange or re-structure [6,7]. In addition, because the surface bonding around the periphery are destroyed as the result of higher shear rate, some inner pores hidden by these aggregates were re-available to other small but compact clusters or particles. If they are filled up by those clusters or particles, the fractal dimension of flocs would evidently increase.

\subsection{Floc size and strength characterization}

The aggregates size distribution is another important parameter, which directly reflects the evolution of colloid aggregates. Moreover, the size distribution has a tight relationship with fractal dimension and strength of aggregates [38].

As shown in Fig. 3, after the slow stirring phase, flocs formed in stable $40 \mathrm{rpm}$ have reached a $d(50)$ floc size of $600 \mu \mathrm{m}$ and flocs developed under gradually increased shear rates have $d(50)$ floc size of $450 \mu \mathrm{m}$ under the charge neutralization (Fig. 3a). The flocs, grown under stable $60 \mathrm{rpm}$ and $60+40$ conditions, exhibit some decrease after reaching the peak of size. Similar phenomenon was observed by Gregory and Rossi [15]. Unfortunately, the reasons for this behavior are not fully understood [25]. In all cases, floc size is immediately decreased sharply during the following increased shear. After breakage, flocs are exposed in the $40 \mathrm{rpm}$ shear rate about $20 \mathrm{~min}$, the $d(50)$ size of all flocs regrows to another new plateau. Flocs formed in " $40+60$ " and " $60+40$ " conditions have larger size than other flocs, while flocs developed under stable $60 \mathrm{rpm}$ are the smallest.

Flocs formed in " $40+60$ " conditions and in stable $60 \mathrm{rpm}, d(90)$ distribution shows different behavior compared with other flocs under charge neutralization (Fig. 3b). Especially the size of " $40+60$ " flocs only slightly decreases during the breakage stage, while the pattern of breakage and regrowth behavior of the other three flocs 


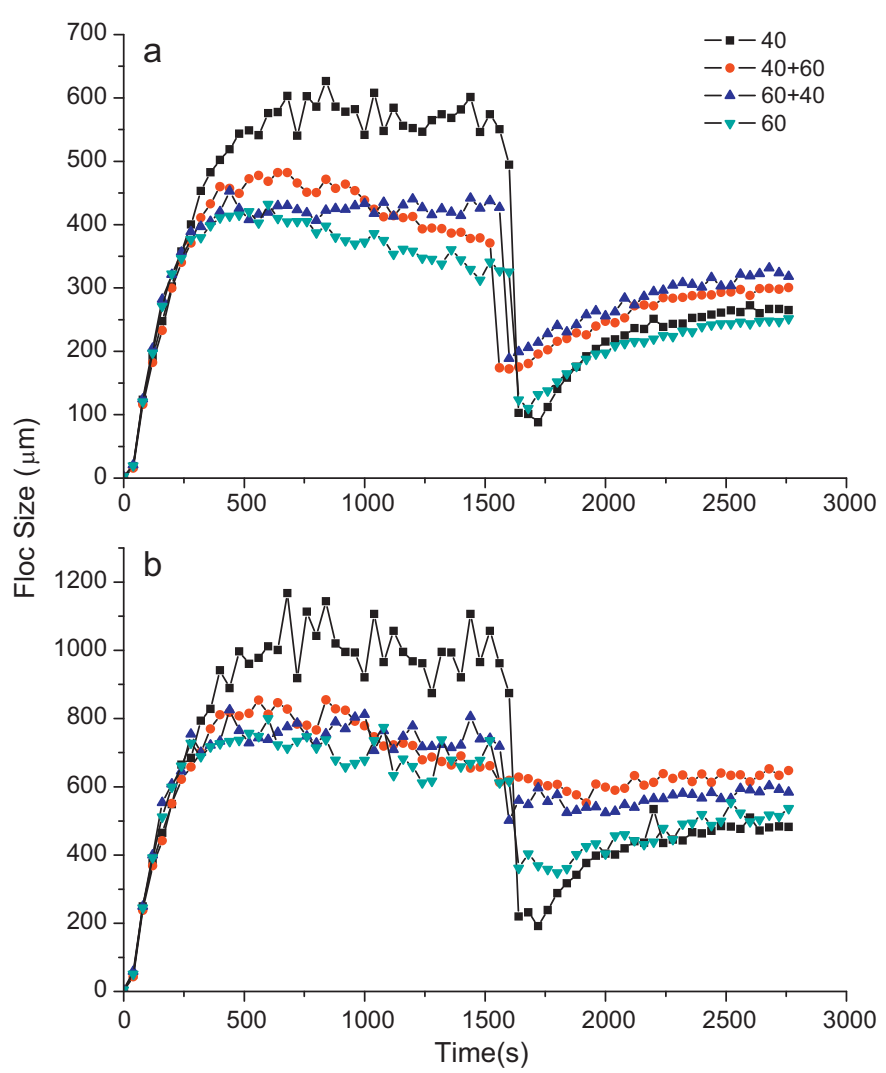

Fig. 3. Floc size distribution in the first group (a) floc size distribution with $d(50)$ (b) floc size distribution with d (90).

is similar to $d(50)$ at the charge neutralization point. The reason may be that the strength of flocs formed in " $40+60$ " condition is larger than other flocs.

Table 2 shows the strength factors and recovery factors.

The strength factor values in Table 2 show that " $40+60$ " flocs and " 60 " flocs have better ability to resist shear with larger strength factors. Thus, the associated size change at the breakage stage is smaller than the other two conditions. After breakage, floc regrowth is observed with recovery factor of $63 \%$ and $67 \%$ for " $40+60$ " and "60" flocs respectively, while flocs formed in stable $40 \mathrm{rpm}$ has the lowest recovery factor of $37 \%$. Obviously, the flocs grown in gradually increased shear have better capability to resist the hydraulic shear than the " 40 " flocs.

Taking account of the method introduced in Section 2, strength of fractal aggregates can be calculated as shown in Table 3 .

It can be seen that the sequence of floc strength is " $40+60$ " > " 60 " > " $60+40$ " > " 40 " during charge neutralization. The result is consistent with the results in Table 2 . It indicates that not only the bonding forces between primary particles, but also the distribution of porosity plays a significant role in the strength of aggregates. Because the smaller clusters or particles fill the inner porosity of aggregates when the shear rate increases, the porosity of aggregates will decrease and the strength of aggregates will be improved. Thus, as shown in Fig. 3, some large size aggregates could survive during the high shear rate.

Table 3(b) shows the floc strength at the end of regrowth stage. The flocs formed in " $40+60$ " conditions are stronger than other flocs. This phenomenon also reflects that " $40+60$ " flocs have better performance to resist the fluctuation of hydraulic conditions. The decrease percentage of " 40 " flocs is negative reveals that the strength of " 40 " flocs is enhanced after breakage because the structure is more compact than which before breakage.
Table 3

Strength of flocs before and after breakage calculated by Eq. (10).

\begin{tabular}{|c|c|c|c|c|c|}
\hline \multicolumn{6}{|l|}{ (a) } \\
\hline Runs & \multicolumn{2}{|l|}{$d f(\mu \mathrm{m})$} & $\mathrm{d} 0(\mu \mathrm{m})$ & $D F$ & $\tau B$ \\
\hline $40+60$ & 397.8 & & 4 & 2.54 & $0.0091 \mathrm{~F}$ \\
\hline 60 & 380.1 & & 4 & 2.52 & $0.0089 \mathrm{~F}$ \\
\hline $60+40$ & 446.9 & & 4 & 2.48 & $0.0065 \mathrm{~F}$ \\
\hline 40 & 595.7 & & 4 & 2.45 & $0.0049 \mathrm{~F}$ \\
\hline \multicolumn{6}{|l|}{ (b) } \\
\hline Runs & $D f(\mu \mathrm{m})$ & $d 0(\mu \mathrm{m})$ & $D F$ & $\tau B$ & Decr. Perc. (\%) \\
\hline $40+60$ & 299.3 & 4 & 2.43 & $0.0065 \mathrm{~F}$ & 28.6 \\
\hline 40 & 266.1 & 4 & 2.38 & $0.0056 \mathrm{~F}$ & -14.3 \\
\hline $60+40$ & 324.4 & 4 & 2.35 & $0.0043 \mathrm{~F}$ & 33.7 \\
\hline 60 & 249.0 & 4 & 2.39 & $0.0062 \mathrm{~F}$ & 30.3 \\
\hline
\end{tabular}

$d_{f}$ : mean of the last three $D[3,4]$ measured before breakage. Decrease Percentage calculated by $\left(1-\tau_{B}\right.$ in Table $3(\mathrm{~b}) / \tau_{B}$ in Table $\left.3(\mathrm{a})\right) \times 100 \%$

\subsection{Size distributions of charge-neutralization flocs}

Fig. 4 showed the bimodal distributions of colloid aggregates size during the breakage stage at the charge neutralization point The peak of size distribution in $40+60$ is around $100 \mu \mathrm{m}$ and $500 \mu \mathrm{m}$, while the peak of stable $40 \mathrm{rpm}$ shear condition is around $100 \mu \mathrm{m}$ and $450 \mu \mathrm{m}$. Obviously, the smaller peaks under both shear conditions are almost same except different percentage. But the larger peaks have visible differences. Especially, the percentage of colloid aggregates larger than $400 \mu \mathrm{m}$ in $40+60$ is much greater than that of in stable $40 \mathrm{rpm}$ shear condition and increases with the time during the breakage stage.

The percentage of flocs around the $450 \mu \mathrm{m}$ formed in the $60+40$ is larger than flocs formed in " $40+60$ ". It seems contradictory with the results of Tables 2 and 3 . It is obviously that the peaks of " $60+40$ " flocs decreased as the development of breakage stage, while other flocs almost have the same size and volume during the breakage stage. According to Eq. (8), the strength at this shear rate is lower than the others. This is the reason why there is obvious decreasing of peak during the breakage stage. However, because the primary clusters which formed the " $60+40$ " flocs grew at the relatively higher shear rate than " 40 " flocs, these clusters are more compact and stronger than " 40 " flocs but weaker than "60" flocs. Another seemingly inconsistent phenomenon is that the flocs formed in $60 \mathrm{rpm}$ conditions have higher percentage of flocs around $500 \mu \mathrm{m}$. However, if pay attention to the flocs larger than $800 \mu \mathrm{m}$, it is obviously that the volume percentage of " $40+60$ " flocs is about $6 \%$, while other flocs is less than $1 \%$. In addition, $40+60$ flocs and 60 flocs have about $35 \%$ and $30 \%$ between $300 \mu \mathrm{m}$ to $800 \mu \mathrm{m}$. This coincides with the results in Table 3.

\section{Potential application in the engineering aspects}

The strength of flocs influences the efficiency of water treatment reactors. Therefore, compact and strong flocs play a key role in the design of the effective flocculation or coagulation reactors. Moreover, they are influenced by the cavities distribution in flocs. Enhanced flocculation process by means of decreasing the large pores may be an aspect to improve the solid/liquid separation efficiency in coagulation and flocculation. And the reactors that can produce the gradually increased shear rate will be an economic and practical method to achieve this aim.

Floc structure is key factor to analyze the characters of flocs. To obtain the desired structures, we can control and optimize the influencing factors involved. The prediction of flocs dynamic behavior can be derived theoretically by the above theoretical model. Thus, we can not only improve the design of flocculation reactors, but 

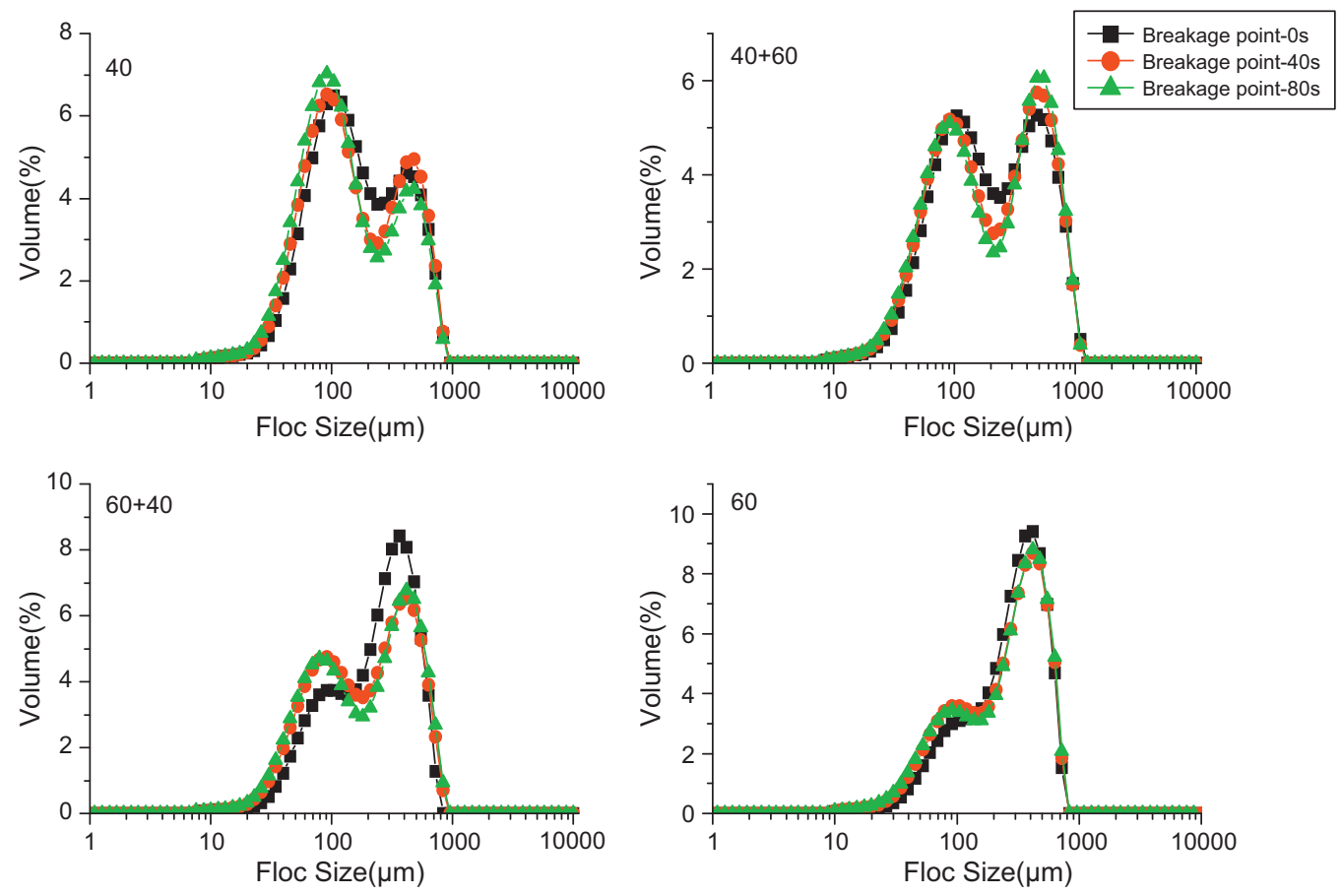

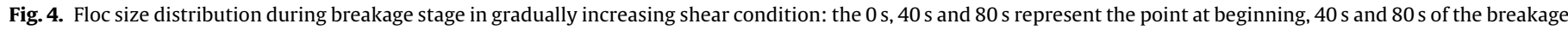
stage, respectively.

also promote optimization the existing reactors for desired engineering flocs structure. The gradually increased shear rate may be an economic and practical method to improve the strength of flocs.

\section{Acknowledgements}

This work is supported by the NSF of China under 50921064, 51025830 and 50721006 . The kind comments from the anonymous reviewers are gratefully acknowledged.

\section{References}

[1] T. Li, Z.Zhu, D.S. Wang, C.H. Yao, H.X.Tang, Characterization of floc size, strength and structure under various coagulation mechanisms, Powder Technol. 168 (2006) 104-110.

[2] E.L Sharp, P. Jarvis, S.A. Parsons, B. Jefferson, The impact of zeta potential on the physical properties of ferric-NOM flocs, Environ. Sci. Technol. 40 (2006) 3934-3940.

[3] C. Rattanakawin, R. Hogg, Aggregate size distributions in flocculation, Colloids Surf. A: Physicochem. Eng. Aspects Sci. 177 (2001) 87-98.

[4] P. Jarvis, B. Jefferson, J. Gregory, S.A. Parsons, A review of floc strength and breakage, Water Res. 39 (2005) 3121-3137.

[5] D. Bouyer, C. Coufort, A. Line, Z. Do-Quang, Experimental analysis of the floc size distribution in a 1-L jar under different hydrodynamics and physicochemical conditions, J. Colloid Interface Sci. 292 (2005) 413-428.

[6] A. Thill, S. Veerapaneni, B. Simon, M. Wiesner, J.Y. Bottero, D. Snidaro, Determination of Structure of aggregates by confocal scanning laser microscopy, J Colloid Interface Sci. 204 (1998) 357-362.

[7] A. Thill, S. Lambert, S. Moustier, P. Ginestet, J.M. Audic, J.Y. Bottero, Structural interpretations of static light scattering patterns of fractal aggregates, J. Colloid Interface Sci. 228 (2000) 386-392.

[8] X.Y. Li, B.E. Logan, Collision frequencies of fractal aggregates with small particles by differential sedimentation, Environ. Sci. Technol. 31 (1997) 1229-1236.

[9] X.Y. Li, B.E. Logan, Collision frequencies between fractal aggregates and small particles in a turbulently sheared fluid, Environ. Sci. Technol. 31 (1997) 1237-1242.

[10] X.Y. Li, P.C.L. Ruby, Determination of the fractal dDimension of microbial flocs from the change in their size distribution after breakage, Environ. Sci. Technol. 39 (2005) 2731-2735.

[11] S.J. Jung, R. Amal, J.A. Raper, Monitoring effects of shearing on floc structure using small-angle light scattering, Powder Technol. 88 (1996) 51-54.

[12] P.T. Spicer, S.E. Pratsinis, J. Raper, R. Amal, G. Bushell, G. Meesters, Effect of shear schedule on particle size, density and structure during flocculation in stirred tanks, Powder Technol. 97 (1998) 26-34.
[13] P Jarvis, B. Jefferson, S.A. Parsons, Breakage, regrowth, and fractal nature of natural organic matter flocs, Environ. Sci. Technol. 39 (2005) 23072314.

[14] P. Tang, J. Greenwood, J.A. Raper, A model to describe the settling behavior of fractal aggregates, J. Colloid Interface Sci. 247 (2002) 210-219.

[15] J. Gregory, L. Rossi, Dynamic testing of water treatment coagulants, Water Sci. Technol.: Water Supply 1 (2001) 65-72.

[16] T.A. Witten, L.M. Sander, Diffusion-limited aggregation: a kinetic critical phenomenon, Phys. Rev. Lett. 47 (1981) 1400-1403.

[17] H. Tanaka, T. Araki, Simulation method of colloidal suspensions with hydrodynamic interactions: fluid particle dynamics, Phys. Rev. Lett. 85 (2000) 1338-1341.

[18] T. Terao, T. Nakayama, Sol-gel transition of reversible cluster-cluster aggregations, Phys. Rev. E 58 (1998) 3490-3494.

[19] K.H. Gardnera, T.L. Theisb, T.C. Youngb, Colloid aggregation: numerical solution and measurements, Colloids Surf A: Physicochem. Eng. Aspects Sci. 141 (1998) 237-252.

[20] M.Y. Lin, H.M. Lindsay, D.A. Weitz, R.C. Ball, R. Klein, P. Meakin, Universality in colloid aggregation, Nature 339 (1989) 360-362.

[21] N. Tambo, Y. Watanabe, Physical characteristics of floc-: the floc density function and aluminium floc, Water Res. 13 (1978) 409-419.

[22] N. Tambo, H. Hozumi, Physical characteristics of flocs-: strength of flocs, Water Res. 13 (1979) 421-427.

[23] D.H. Bache, E. Rasool, D. Moffat, F.J. McGilligan, On the strength and character of alumino-humic flocs, Water Sci. Techenol. 40 (1999) 81-88.

[24] P. Jarvis, B. Jefferson, S.A. Parsons, How the natural organic matter to coagulant ratio impacts on floc structure properties, Environ. Sci. Technol. 39 (2005) 8919-8924.

[25] J. Gregory, M.A. Yukselen, The reversibility of floc breakage, Int. J. Miner. Proc. 73 (2004) 251-259.

[26] R.K. Chakrabortia, K.H. Gardnerb, J.F. Atkinsona, et al., Changes in fractal dimension during aggregation, Water Res. 37 (2003) 873-883.

[27] C.R. O'Melia, Coagulation and sedimentation in lakes, reservoirs and water treatment plants, Water Sci. Technol. 37 (1998) 129-135.

[28] J. Gregory, The role of floc density in solid-liquid separation, Filtr. Sep. 35 (1998) 367-371.

[29] P. Meakin, Fractal aggregates, Adv. Colloid Interface Sci. 28 (1988) 249331.

[30] S. Tang, Y. Ma, C. Shiu, Modeling the mechanical strength of fractal aggregation, Coloids Surf. A 180 (2001), 7-16.

[31] C. Kranenburg, Effects of floc strength on viscosity and deposition of cohesive suspensions, Continent. Shelf Res. 19 (1999) 1665-1680.

[32] T.S. Yang, X.Z. Xiong, X.L. Zhan, M.Q. Yang, On flocculaton of cohesive fine sediment, Hydro-Sci. Eng. 2 (2003) 65-77 (In Chinese).

[33] S. Tang, A model to describe the settling behavior of fractal aggregates, Colloids Surf. A: Physicochem. Eng. Aspects Sci. 157 (1999) 185-192.

[34] A. Thill, M. Wagner, J.Y. Bottero, Confocal scanning laser microscopy as a tool for the determination of 3D floc structure, J. Colloid Interface Sci. 220 (1999) 465-467. 
[35] P.T. Spicer, Shear-induced aggregation-fragmentation: mixing and aggregate morphology effects, Doctor Dissertation, 1997.

[36] R.M. Wu, D.J. Lee, T.D. Waite, J. Guan, Multilevel structure of sludge flocs, J. Colloid Interface Sci. 252 (2002) 383-392.
[37] P.T. Spicer, S.E. Pratsinis, M.D. Trennepohl, Coagulation and fragmentation: the variation of shear rate and the time lag for attainment of steady state, Ind. Eng. Chem. Res. 35 (1996) 3074-3080.

[38] K. Rastegari, W.Y. Svrcek, H.W. Yarranton, Kinetics of asphaltene flocculation, Ind. Eng. Chem. Res. 43 (2004) 6861-6870. 